\title{
Friction Coefficient of Rough Indoor Flooring Materials
}

\author{
F.H. Ezzat*, A.T. Hasouna $* *$ and W.Ali*** \\ *Faculty of Engineering, Minia University, \\ **El-Minia High Institute of Technology, El-Minia, Egypt, and \\ *** Faculty of Engineering, Taif University, Saudi Arabia \\ wahyos@hotmail.com
}

\begin{abstract}
The present study investigates the effect of the surface roughness of polymeric indoors floorings on the static friction of bare foot as well as foot wearing cotton and polymeric socks under dry, water, water +5.0 vol. $\%$ soap, oil and water +5.0 vol. \% oil lubricated sliding conditions. Polymeric floor sheets of different roughness ranging from 0.05 and $11.0 \mu \mathrm{m}$ were tested. The tested material is commonly used in entrance areas or corridors and in the sport halls. Cotton and polymeric socks as well as bare foot were frictionally tested. The results were compared to the friction caused by shoes as simulated by rubber test specimens of vee shape treads were prepared in the form of square sheets of $100 \times 100 \mathrm{~mm}, 10.0 \mathrm{~mm}$ thickness. Experiments were carried out using a test rig designed and manufactured to measure the friction coefficient between the foot and the tested polymeric flooring materials.
\end{abstract}

The experimental results showed that, at dry sliding, friction coefficient of rubber decreased with increasing surface roughness, while for bare foot and polymeric socks, friction coefficient decreased down to minimum then increased with increasing the surface roughness. Besides, friction coefficient decreased with increasing applied load. Minimum friction was observed at surface roughness ranging between 6-9 $\mu \mathrm{m}$. In water lubricated sliding, friction coefficient of rubber increased up to maximum then decreased with increasing surface roughness. Maximum friction values were observed at surface roughness values ranging from 1.5 to $2.0 \mu \mathrm{m} \mathrm{R}$. Cotton socks showed the highest friction coefficient followed by rubber, bare foot then polymeric socks at $11 \mu \mathrm{m} \mathrm{R}_{\mathrm{a}}$. Friction coefficient drastically decreased with increasing surface roughness at water and detergent lubricated sliding. For the tested flooring materials lubricated by oil, friction coefficient of rubber increased up to maximum values then decreased with increasing the surface roughness of the flooring 


\begin{abstract}
materials. The maximum friction values were noticed at $4.0 \mu \mathrm{m} \mathrm{R}$. Bare foot displayed drastic reduction in friction coefficient, while cotton socks showed the highest values. When water was diluted by 5.0 wt. \% oil, rubber smooth flooring surface displayed values of friction coefficient close to that observed for hydrodynamic lubrication where the two sliding surfaces are separated by the fluid film. As the roughness increased the fluid film was broken and friction increased. Cotton socks showed the highest friction compared to bare foot and polymeric socks.
\end{abstract}

Keywords: Surface Roughness, Polymeric Friction Materials, Friction Coefficient, Flooring Materials, Rubber.

\title{
1. Introduction
}

The changes in the surface properties and frictional characteristics of flooring materials can be expected in daily use because they are subject to mechanical wear, ageing, soiling and maintenance ${ }^{[1]}$. In sport halls the flooring surfaces are usually changed mainly through mechanical wear, periodic cleaning processes and material transfer from shoe soles (Elastomer and dirt particles). Coefficients of friction were measured periodically over a period of 30 months on the surfaces of five types of floor coverings in a new sport complex ${ }^{[2]}$. Surface roughness is known to be a key factor in determining the slip resistanmce of the floors. Surface changes through mechanical wear ranged from smoothing to roughening ${ }^{[3,4]}$, depending on flooring material and surface characteristics.

The effect of surface roughness on the friction coefficient of ceramic rubbing against rubber and leather, was investigated ${ }^{[5]}$. Glazed floor tiles of different roughness ranging from 0.05 to $6.0 \mu \mathrm{m}$ were tested. The test results showed that, friction coefficient decreased down to minimum then increased with increasing the surface roughness of the ceramic surface.

Measurements of the static friction coefficient between rubber specimens and ceramic surfaces were carried out at dry, water lubricated, oil, oil diluted by water and sand contaminating the lubricating fluids ${ }^{[6-8]}$. It was observed that, dry sliding of the rubber test specimens displayed the highest value of friction coefficient. For water lubricated ceramics, the value of the friction coefficient decreased as compared to dry sliding. For oil lubricated ceramic, friction coefficient decreased with increasing grooves height on the surface of the rubber specimens. The decrease can be attributed to the well adherence of oil on the rubber surface, where a lubricating film was formed. Besides, diluting oil by water displayed 
values of friction much lower than that observed for oil lubricated condition. As for ceramic lubricated by water and soap and contaminated by sand, friction coefficient increased significantly compared to the sliding conditions of water and soap only. In the presence of oil and sand on the sliding surface, the friction slightly increased. This is believed to be caused by sand embedment in rubber surface and consequently the contact took place between ceramic and embedded sand particles. At lubricated sliding of oil and water contaminated by sand, the friction presented higher value than that of oil and sand contaminated sliding conditions.

Slip resistance of flooring materials is one of the major environmental factors affecting walking and materials handling behaviors. Floor slipperiness may be quantified using the static and dynamic friction coefficient ${ }^{[9]}$. Certain values of friction coefficient were recommended as the slip-resistant standard for unloaded, normal walking conditions $^{[10,11]}$. Relatively higher static and dynamic friction coefficient values may be required for safe walking when handling loads.

Researches revealed significant correlations between surface roughness of shoes and friction coefficient for a given floor surface ${ }^{[12-15]}$. Abrasion of rubber solings in steps with increasingly coarse grit gradually raised the roughness in parallel with a rise in the friction coefficient on water wet surfaces. Dense rubbers never developed the same order of roughness, and they became smooth and polished when worn on ordinary floors or with mechanical polishing.

Friction between the insole, sock and foot has significant impact on the perception of comfort and the risk of injury of the wearers. Low friction allows the foot to move easily in the shoe. However, excessive movement can result in feeling of insecurity and may generate pressure and rubbing between the top and upper part of the foot and the shoe ${ }^{[16]}$. Rubbing in shoe includes friction between the foot and the inner surface of sock, and that between the outer surface of sock and shoe. Too low friction in both interfaces may lead to excessive movement of foot in shoe and induces discomfort feeling of insecurity. It was found that the difference of friction coefficient among interfaces provide insight into where slip occurs ${ }^{[17]}$. It was predicted that slip would be expected at the 
interface of lower friction coefficient rather than the interface of higher friction coefficient. It was recommended to set low friction on one side to allow foot sliding, and high friction on the other side to provide appropriate level of resistance to avoid excessive movement.

It was found that wearing sock of low friction against the insole to allow more relative sliding between the plantar foot and footwear was found to reduce the shear force significantly ${ }^{[18]}$. Socks change the frictional properties between the foot-shoe interface. Abrasion of the foot skin can be avoided by reducing the shear at the contact interfaces by using socks made from textile fibers of low frictional coefficients ${ }^{[19]}$. The mechanical effect of sock with different frictional properties on foot was investigated by finite element models ${ }^{[20]}$. Wearing sock can reduce friction and allow the foot to slip on the insole, hence to reducing the shear. It was found that, ${ }^{[21]}$, the shear stresses for objects wearing nylon hose were significantly lower than the values for hose-free objects. It was reported that by using the teflon fiber to the sock soles to impart an extremely low friction value, the socks reduced the occurrences of blister by around $90 \%$ in athletes ${ }^{[22]}$. Shear is possibly a main mechanical risk factor of blister development. Therefore, reduction of shear is crucial in preventing the foot lesion development.

In the present work, the effect of the surface roughness of polymeric floor sheets of different roughness on the static friction coefficient displayed by rubber, bare foot as well as foot wearing cotton and polymeric socks under dry, water, water +5.0 vol. $\%$ soap, oil and water +5.0 vol. $\%$ oil lubricated sliding conditions was investigated.

\section{Experimental}

Experiments were carried out using a test rig designed and manufactured to measure the friction coefficient between the foot and the floorings through measuring both the friction and normal forces. The tested flooring materials are placed in a base supported by two load cells. The first measures the horizontal force (friction force) and the second measures the vertical force (applied load). Friction coefficient is determined by the ratio between the friction force and the normal load. 
The arrangement of the test rig is shown in Fig. 1. The flooring materials were thoroughly cleaned with soap water to eliminate any dirt and dust and carefully dried before the tests. Bare foot, cotton and polymeric socks (polyester) were loaded against dry, water, water +5.0 vol. \% soap, oil (sun flower oil), water +5.0 vol. $\%$ oil lubricated polymeric flooring materials. The tested flooring materials of Vinyl were in the form of a quadratic sheet of $0.4 \mathrm{~m} \times 0.4 \mathrm{~m}$ and $3.0 \mathrm{~mm}$ thick. The surface roughness of the flooring materials was measured using a Mitutoyo Surftest 301 profilometer. The roughness measurements were taken in the same direction as the friction coefficient measurements. The travel distance of the profilometer was $12.5 \mathrm{~mm}$ with a cut-off length of 2.5 $\mathrm{mm}$. Eight measurements were taken for each sheet. The surface roughness ranged from 0.5 to $11 \mu \mathrm{m} \mathrm{Ra}$, (the center line average of surface heights, CLA). Friction test was carried out at different values of normal load exerted by foot which ranged between 10 to $850 \mathrm{~N}$. Rubber test specimens were prepared in the form of square sheets of $100 \times 100$ $\mathrm{mm}$ and $10.0 \mathrm{~mm}$ thick. Vee shape treads, of $2.0 \mathrm{~mm}$ height, $4.0 \mathrm{~mm}$ width and $2.0 \mathrm{~mm}$ depth, were introduced in rubber test specimens, Fig. 2. The rubber specimens were adhered on wood blocks. The hardness of the rubber was 45 on a Shore-A hardness meter.

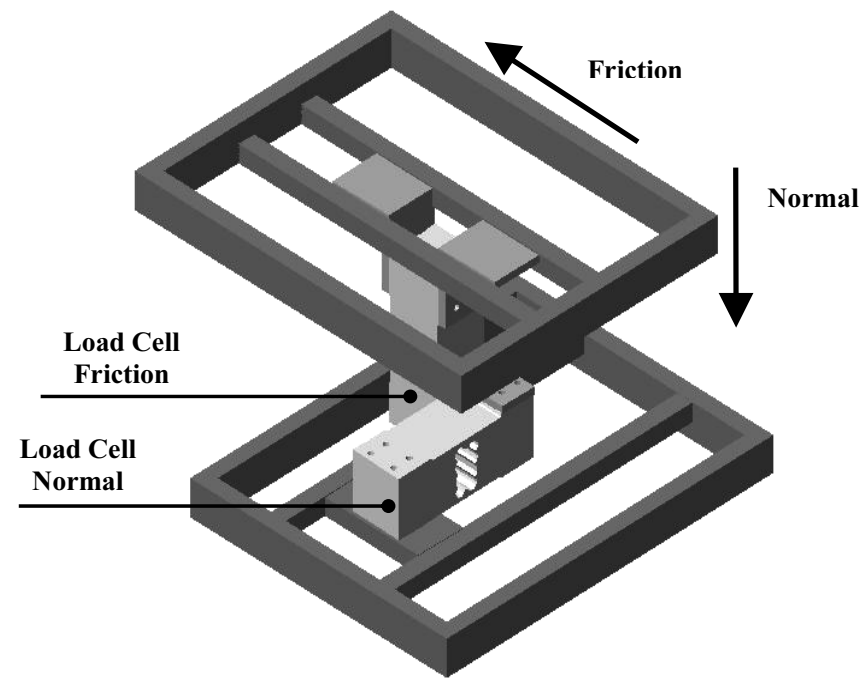

Fig. 1. Arrangement of the test rig. 


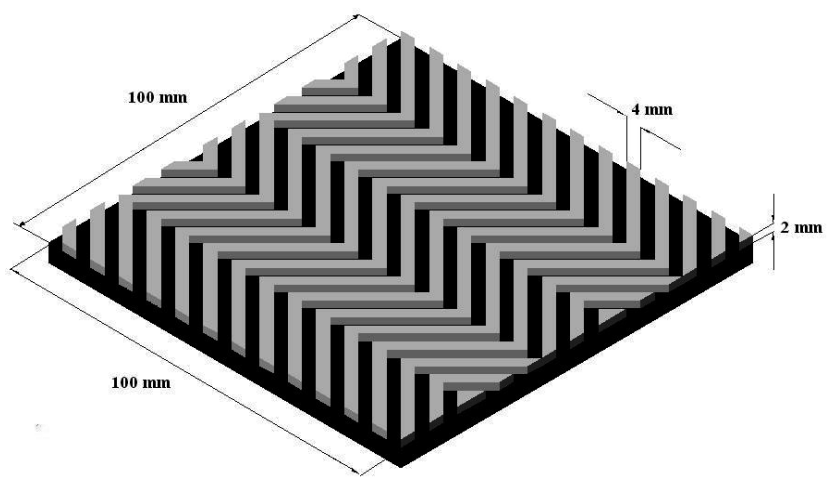

Fig. 2. Rubber test specimen.

The sliding conditions were dry, water, water-detergent mixture, oil, and water-oil mixture. Water was replenished on the tested flooring materials, where the amount of water for each replenishment was $10 \mathrm{ml}$ to form consistent water film covering the sliding surface. In the waterdetergent condition, a 5.0 vol. \% detergent solution was applied to the flooring. In the oily condition, $2 \mathrm{ml}$ of vegetable oil (sun flower oil) was spread on the flooring using a paintbrush. After each measurement, all contaminants were removed from the flooring materials using absorbent papers. The flooring materials were then rinsed using water. In the oily condition, the sliding surfaces were cleaned using a detergent solution to remove the oil, rinsed using tap water and air blown using hair dryer after the cleaning process.

\section{Results and Discussion}

Tests were carried out at different values of normal load exerted by foot of the operator. The tested socks were worn by the foot of the operator during the test so that they were kept stretched. The operator pressed his foot on the flooring materials pushing forward until slip occurred. Then the maximum friction and normal forces were measured. The ratio of the two forces indicated the static friction coefficient. In the present work, the results of the two values of load of 100 and $800 \mathrm{~N}$ are illustrated. At dry sliding condition, friction coefficient displayed by rubber, bare foot as well as cotton and polymeric socks is shown in Fig. 3 and 4 at applied loads of 100 and $800 \mathrm{~N}$ respectively. Friction coefficient decreased with increasing surface roughness. For smooth surfaces, the maximum adhesion was attained, the interfacial area had a maximum 
value, the mechanism of molecular stick-slip process is responsible for the increased adhesion component of friction and consequently friction coefficient displayed relatively higher values. The increase of surface roughness decreased friction coefficient due to the decrease of the contact area as well as adhesion. It is clearly shown that there was a drastic decrease in the friction values with increasing normal load due to saturation of the rubber asperities and rubber filling the gaps between the track asperities, where the rubber in the contact area deformed in such a manner as to completely follow the short-wavelength surface roughness profile of the counterface.

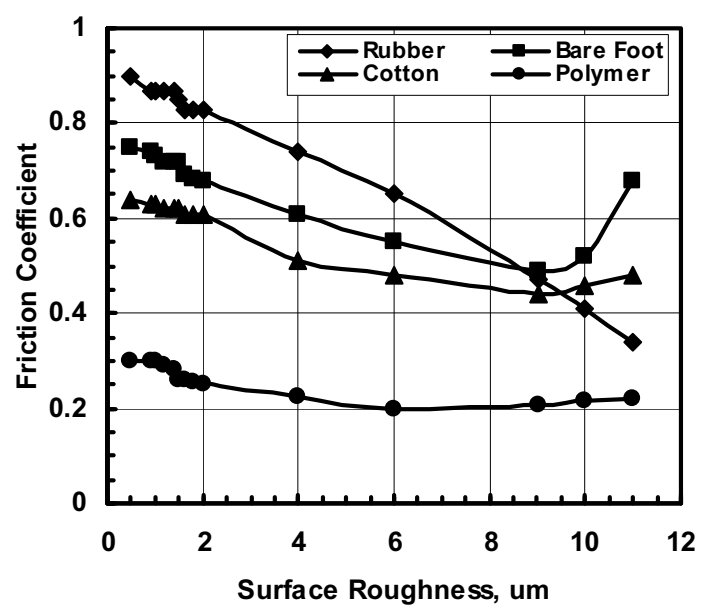

Fig. 3. Dry sliding friction coefficient at $100 \mathrm{~N}$ load.

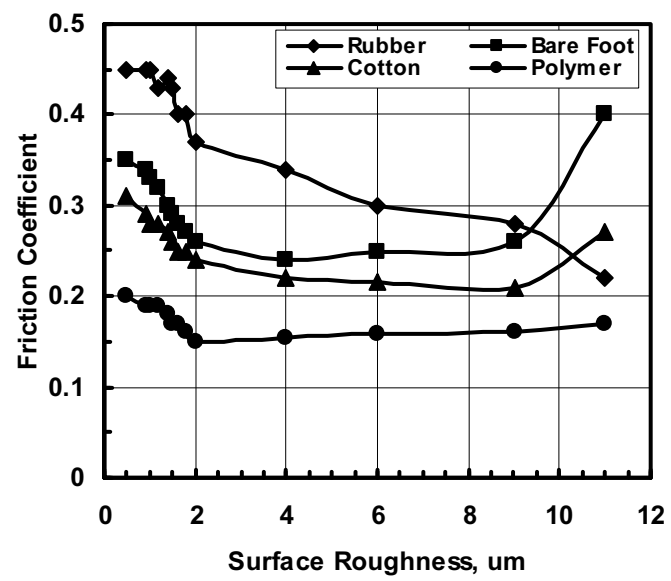

Fig. 4. Dry sliding friction coefficient at $800 \mathrm{~N}$ load. 
At $11.0 \mu \mathrm{m}$ surface roughness, bare foot displayed the highest friction coefficient followed by cotton and polymeric socks, Fig. 3. Generally, friction coefficient decreased down to minimum then increased with increasing the surface roughness of the flooring materials. The friction coefficient-surface roughness relationship can be divided into three stages. The first stage shows relatively high friction for smooth tested flooring materials, where they exhibited relatively high friction coefficient due to the maximum adhesion attained since the contact area had a maximum value. Thus a dissipative stick-slip process on a molecular level is fundamentally responsible for the increased adhesion and consequently the increase of friction coefficient. The second stage of friction coefficient, where its value decreased down to minimum, can be explained on the basis that, as the surface roughness increased the area of contact between foot and the tested flooring materials decreased. As a result of this, the adhesion between the sliding surfaces decreased causing significant decrease in friction coefficient. Further increase of the surface roughness of the tested flooring materials caused friction increase (the third stage). The adhesive interaction between the foot and the tested flooring materials induced additional visco-elastic deformations of the foot in such a manner that the foot completely deformed to fill-out the short-wavelength surface roughness profile. This gives an additional contribution to the friction force and consequently, friction coefficient increases. The minimum friction values observed were $0.44,0.42$ and 0.2 displayed by bare foot, cotton and polymeric socks respectively, while the minimum friction displayed by rubber was 0.32 .

Wearing cotton socks showed the same trend in friction coefficient but the values were lower than bare foot, where maximum and minimum friction coefficient values were 0.65 and 0.45 respectively. Polymeric socks displayed the lowest friction coefficient, where the maximum friction coefficient did not exceed 0.3 . The surface roughness slightly influenced the friction displayed by polymeric socks, Fig. 4. Drastic reduction in friction coefficient was observed at $800 \mathrm{~N}$ load. The maximum values displayed by bare foot $(0.40)$ followed by cotton $(0.31)$ and polymeric socks $(0.20)$. The minimum values of friction coefficient were $0.22,0.19$ and 0.14 displayed by bare foot, cotton and polymeric socks respectively. 
Significant friction decrease was observed for sliding against water lubricated flooring materials, Fig. 5 and 6. The friction coefficient caused by sliding of rubber against the tested flooring is divided into two stages. In the first stage, where the surface roughness ranges from 0.5-2.0 $\mu \mathrm{m}$, friction coefficient increased with increasing surface roughness and it effectively suppressed intermolecular bonding at the surfaces thus the adhesion fell to a very low value compared to dry sliding. As the surface roughness increased the water film was broken and consequently a significant increase in friction coefficient was observed. In the second stage, where friction coefficient decreased with increasing surface roughness, the flooring surface could store more water in the valleys between asperities, where they acted as reservoirs for the water, and the pressure distribution at each asperity summit promoted local drainage effects.

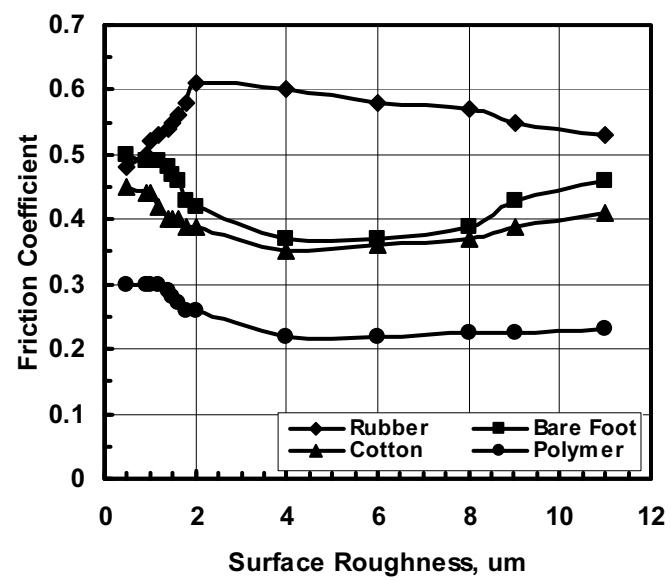

Fig. 5. Friction coefficient of water lubricated flooring at $100 \mathrm{~N}$ load.

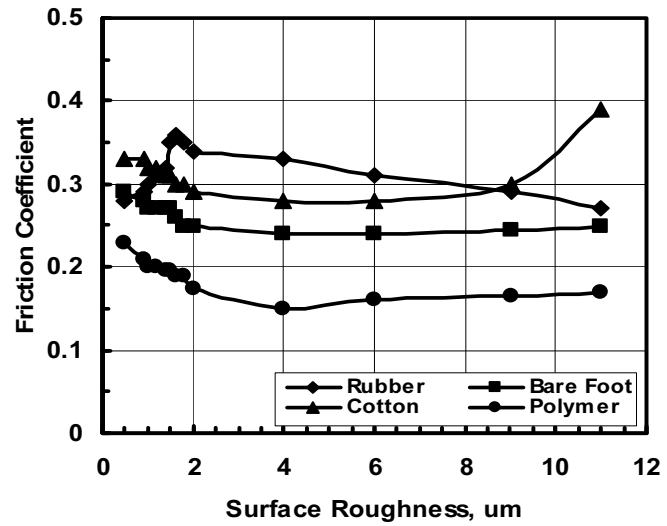

Fig. 6. Friction coefficient of water lubricated flooring at $800 \mathrm{~N}$ load. 
At $100 \mathrm{~N}$ load, bare foot displayed the highest friction values followed by cotton socks, while polymeric socks showed relatively lower friction, Fig. 6. The enhancement of the frictional behaviour of cotton socks may be attributed to their ability to absorb water from the sliding surface and reduce the hydrodynamic effect of the water film. This behaviour may be attributed to the ability of cotton to absorb water from the flooring surface, where this ability increased with increasing load. As the load increased to $800 \mathrm{~N}$, the cotton socks showed the highest friction coefficient as compared with bare foot, where the friction increased with increasing the surface roughness, Fig. 5. The minimum friction values were displayed by polymeric socks, (0.15). At relatively higher values of surface roughness (6.0-11.0 $\mu \mathrm{m})$, friction coefficient for cotton socks increased. This effect may be attributed to the ability of cotton to absorb water from the valleys of the surface roughness and change the contact from mixed into dry one, where the effect of increasing the roughness was clear. Polymeric socks did not absorb the water film covering the sliding surface and consequently friction coefficient significantly decreased. Further increase of surface roughness did not affect friction coefficient.

Mixing water by 5.0 wt. \% detergent like soap caused significant decrease of friction coefficient, Fig. 7, 8. For smooth surfaces (0.5-2.0 $\mu \mathrm{m})$, friction coefficient of rubber drastically decreased with increasing surface roughness. The friction decrease might be attributed to the enhanced adhesion of water film to the sliding surfaces due to the effect of the detergent. As the surface roughness increased, the surface area of the adhering water film increased and consequently friction decreased. For surface roughness values ranging from 2.0 to $11 \mu \mathrm{m}$, friction coefficient slightly decreases. It is noted that friction coefficient for water and detergent lubricated surfaces represented lower values than that displayed by water lubricated surface.

Bare foot displayed the highest friction coefficient followed by cotton and polymeric socks at $11.0 \mu \mathrm{m}$ surface roughness, Fig. 7. Compared to water lubrication, friction coefficient displayed by bare foot increased up to 0.57 . Friction increased also for cotton socks, while drastically decreased for polymeric socks due to the strong adhesion of water and detergent to the polymeric fibres as a result of the electric static charge generated from friction. As the load increased to $800 \mathrm{~N}$, friction coefficient decreased to relatively lower values than that 
displayed by water. Cotton socks showed higher friction than bare foot, Fig. 8, while the polymeric socks showed relatively lower friction. This behaviour recommends the use of cotton socks instead of bare foot and polymeric socks. The friction reduction may be attributed to the strong adhesion of the fluid into the sliding surfaces. Minimum friction coefficient was $0.22,0.19$ and 0.12 for cotton socks, bare foot and polymeric socks.

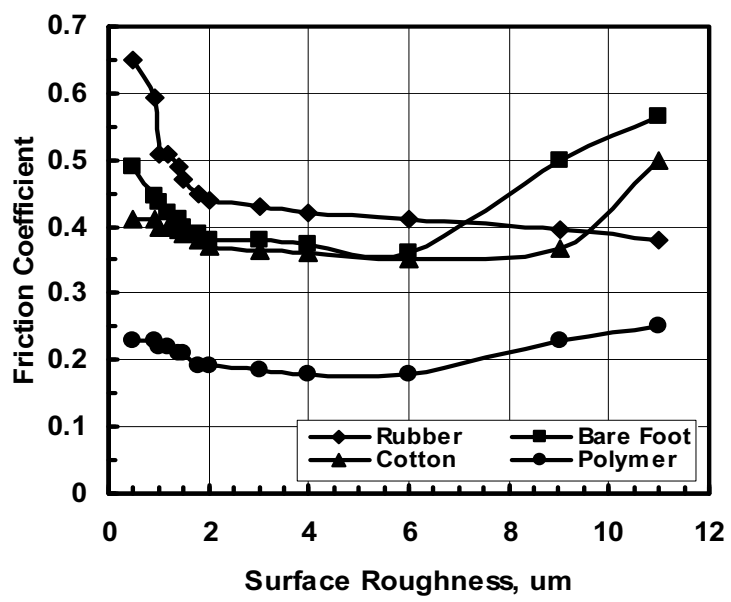

Fig. 7. Friction coefficient of water + detergent lubricated flooring at $100 \mathrm{~N}$.

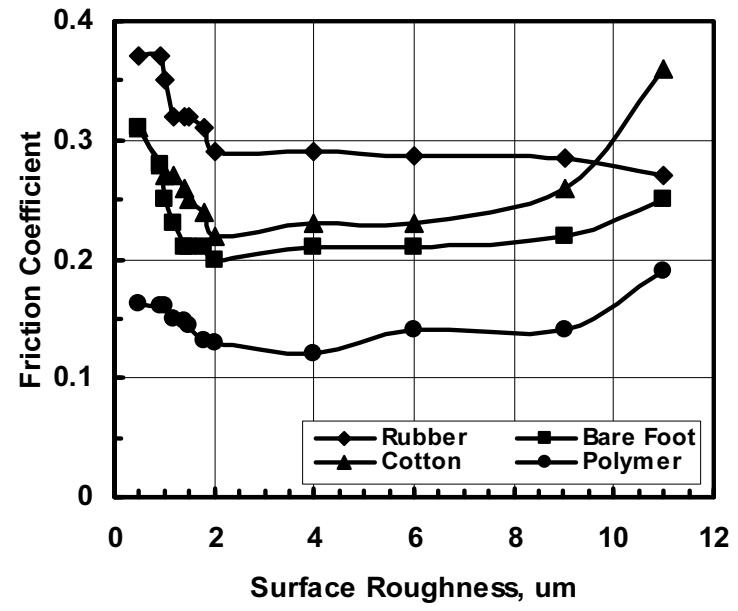

Fig. 8. Friction coefficient of water + detergent lubricated flooring at $800 \mathrm{~N}$.

Friction coefficient generated from the sliding of rubber against oil lubricated polymeric flooring materials is shown in Fig. 9, 10. Friction 
coefficient increased up to maximum values then decreased with increasing the surface roughness of the flooring materials. The maximum friction values were noticed at $4.0 \mu \mathrm{m} \mathrm{R}_{\mathrm{a}}$ surface roughness. It seems that, for smooth surfaces, the oil film formed on the sliding surface was responsible for the friction decrease. The increase of roughness permitted the oil to escape from the contact area into the valleys of the surface roughness. This trend caused significant friction increase. For roughness higher than $4.0 \mu \mathrm{m} \mathrm{R}_{\mathrm{a}}$, slight friction decrease was noticed. This trend was attributed to storing more within the valleys of increased roughness, where the oil could go up to the sliding surface as the rubber pressed the flooring materials. Friction coefficient decreased with increasing applied load due to the increase of the deformation of rubber and displaced the oil up to the contact surface.

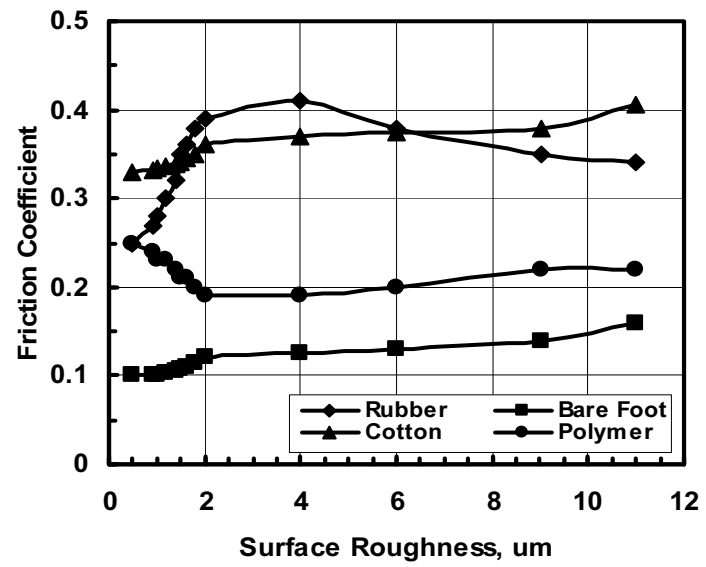

Fig. 9. Friction coefficient of oil lubricated flooring at $100 \mathrm{~N}$.

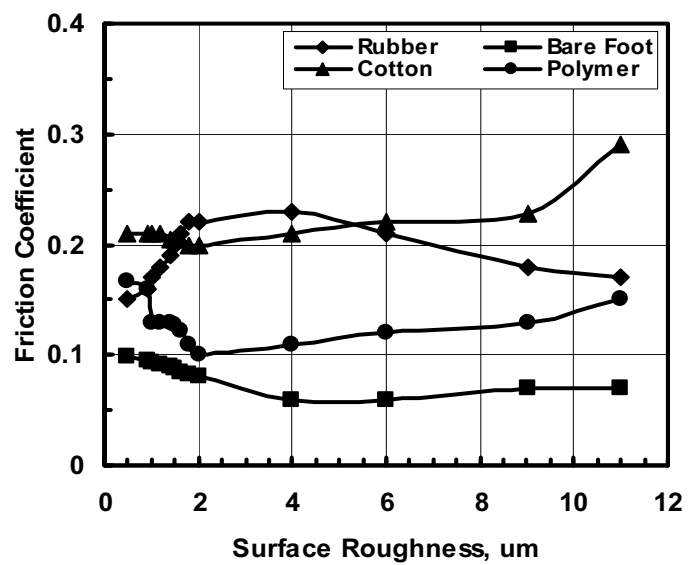

Fig. 10. Friction coefficient of oil lubricated flooring at $800 \mathrm{~N}$. 
A drastic reduction in friction coefficient was displayed by bare foot, while cotton socks showed relatively higher friction, Fig. 9. The relative friction increase observed for cotton socks was attributed to the ability of cotton to absorb oil. In condition of the bare foot and polymeric socks, the oil film was thick enough to decrease the friction. The friction values displayed by bare foot were ranging between 0.1 and 0.16 . This condition of sliding can be classified as mixed lubrication, where the contact area was partially separated by the fluid film. The high oil absorption of cotton enabled the socks to displace the oil film out of the contact area and make the contact between cotton fibres and floorings. The drastic reduction in friction displayed by bare foot may be attributed to the storage of oil in the skin waviness of the foot which feeds oil to the sliding surface. As the load was increased to $800 \mathrm{~N}$, the friction coefficient drastically decreased to 0.06 for bare foot, Fig. 10, while the minimum value of friction coefficient observed for cotton sock was 0.2 .

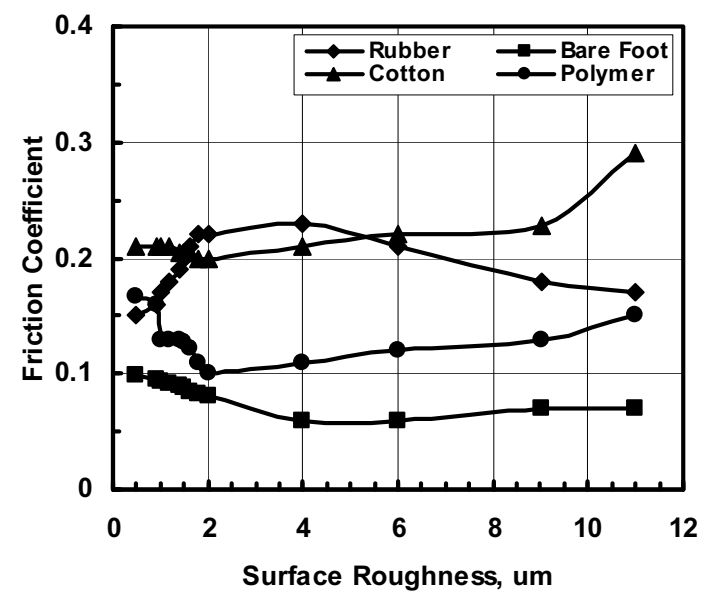

Fig. 11. Friction coefficient of oil + water lubricated flooring at $100 \mathrm{~N}$.

Sliding of rubber against lubricated polymeric floorings by water + 5.0 vol. \% oil caused significant decrease in friction coefficient, Fig. 11, 12. At smooth flooring surface, friction coefficient showed values close to that observed for mixed lubrication where the two sliding surfaces are partially separated by the fluid film. As the roughness increased the fluid film was broken and friction increased. Increasing the applied load caused relative friction decrease due to the increased rubber deformation which displaced the fluid up to the sliding surface, where the rubber was completely deformed and filled-out the short-wavelength surface 
roughness profile of the flooring material. This behaviour gave an additional contribution to the friction force and consequently, friction coefficient increased.

The values of the friction coefficient were higher than that observed for oil. Cotton socks displayed the highest values followed by bare foot and polymeric socks, Fig. 11, at $100 \mathrm{~N}$ load. Friction coefficient increased with increasing surface roughness of the flooring materials for cotton socks and bare foot. Increasing surface roughness had no effect on the frictional behaviour of polymeric socks. The same trend was observed at $800 \mathrm{~N}$ load with relatively lower friction values, Fig. 12. The highest and lowest friction coefficients were 0.23 and 0.12 showed by cotton and polymeric socks respectively. Cotton socks showed a significant increase in friction coefficient with increasing surface roughness, while polymeric socks showed consistent trend of friction.

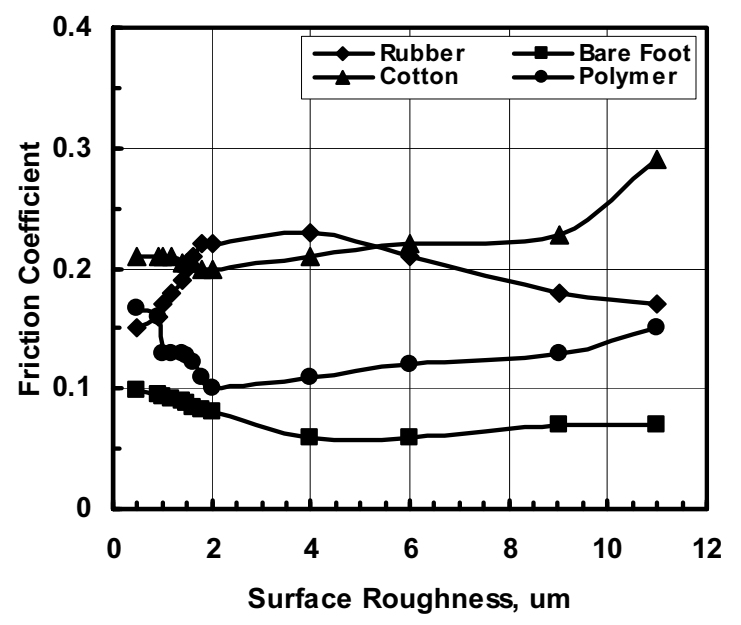

Fig. 12. Friction coefficient of oil + water lubricated flooring at $100 \mathrm{~N}$.

\section{Conclusions}

1. At dry sliding, friction coefficient of rubber decreased with increasing surface roughness. Friction coefficient decreased with increasing applied load. As for bare foot and polymeric socks, friction coefficient decreased down to minimum then increased with increasing the surface roughness. Minimum friction was observed at surface roughness ranging between $6-9 \mu \mathrm{m}$. 
2. At water lubricated sliding, friction coefficient of rubber increased up to maximum then decreased with increasing surface roughness. Maximum friction values were observed at surface roughness values ranging from 1.5 and $2.0 \mu \mathrm{m}$. Cotton socks showed the highest friction coefficient followed by rubber, bare foot then polymeric socks at $11 \mu \mathrm{m}$ surface roughness.

3. At water and detergent lubricated sliding, friction coefficient drastically decreased with increasing surface roughness.

4. At oil lubricated sliding, friction coefficient of rubber increased up to maximum values then decreased with increasing the surface roughness of the flooring materials. The maximum friction values were noticed at $4.0 \mu \mathrm{m}$. Bare foot displayed drastic reduction in friction coefficient, while cotton socks showed the highest values.

5. At water diluted by $5.0 \mathrm{wt}$ \% oil, rubber smooth flooring surface displayed values of friction coefficient close to that observed for hydrodynamic lubrication where the two sliding surfaces are separated by the fluid film. As the roughness increased the fluid film was broken and friction increased. Cotton socks showed the highest friction compared to bare foot and polymeric socks.

\section{References}

[1] Leclercq, S. and Saulnier, H., Floor slip resistance changes in food sector workshops: prevailing role played by fouling, Safety Science, 40: 659 - 673 (2002).

[2] Derler, S., Kausch, F. and Huber, R., Systematic patterns and random fluctuations in time series of coefficients of friction measured on floor surfaces, Safety Science, 43: 391-405 (2005).

[3] Chang, W.R., Kim, I.J., Manning, D.P. and Bunterngchit, Y., The role of surface roughness in the measurement of slipperiness, Ergonomics, 44: 1200-1216, (2001).

[4] Chang, W.R., Li, K.W., Huang, Y.H., Filiaggi, A. and Courtney, T.K., Assessing floor slipperiness in fast-food restaurants in Taiwan using objective and subjective measures, Applied Ergonomics, 35: 401-408 (2004).

[5] Ezzat, F.H., Abdel-Jaber, G.T. and Ali, W.Y., Dry Sliding of Rubber on Glazed Ceramic Tiles, Proceedings of the $7^{\text {th }}$ International Conference of Tribology, EGTRIB 7, December 27 - 28, 2006, Faculty of Engineering, Cairo University, CI, 1-9 (2006).

[6] Samy, A.M., Mahmoud, M.M., Khashaba, M.I. and Ali, W.Y., Friction of Rubber Sliding Against Ceramics, I. Dry and Water Lubricated Conditions, KGK Kautschuk Gummi Kunststoffe 60. Jahrgang, Nr 607, Juni 2007, 322-327 (2007).

[7] Samy, A.M., Mahmoud, M.M., Khashaba, M.I. and Ali, W.Y., Friction of Rubber Sliding Against Ceramics, II. Oil And Oil Diluted By Water Lubricated Conditions, KGK Kautschuk Gummi Kunststoffe 60. Jahrgang, Nr 607, December 2007, 693-696 (2007). 
[8] Samy, A.M., Mahmoud, M.M., Khashaba, M.I. and Ali, W.Y., Friction of Rubber Sliding Against Ceramics, III. Sand Contaminating The Lubricating Fluids, Fourth Assiut University International Conference on Mechanical Engineering Advanced Technology for Industrial Production MEATIP 4, December 12-14, 2006, Assiut, EGYPT (2006).

[9] Li, K.W., Yu, R. and Han, X.L., Physiological and psychophysical responses in handling maximum acceptable weights under different footwear-floor friction conditions, Applied Ergonomics, 38: 259-265 (2007).

[10] Miller, J.M., "Slippery" work surface: toward a performance definition and quantitative coefficient of friction criteria, J. Saf. Res., 14: 145-158 (1983).

[11] Grönqvist, R., Mechanisms of friction and assessment of slip resistance of new and used footwear soles on contaminated floors, Ergonomics, 38: 224-241 (1995).

[12] Manning, D.P., Jones, C. and Bruce, M., A method of ranking the grip of industrial footwear on water wet, oily and icy surfaces, Safety Science, 14: 1-12, (1991).

[13] Manning, D.P. and Jones, C., The superior slip-resistance of soling compound T66/103, Safety Science, 18: 45-60, (1994).

[14] Manning, D.P. and Jones, C., High heels and polished floors: The ultimate challenge in research on slip resistance, Safety Science, 19: 19-29, (1995).

[15] Manning, D.P., Jones, C., Rowland, F.J. and Roff, M., The Surface Roughness of a Rubber Soling Material Determines the Coefficient of Friction on Water Lubricated Surfaces, Journal of Safety Research, 29(4): 275-283 (1998).

[16] Draper, D., Coming down to earth, World Sports Activewear, 5: 53-55 (1999).

[17] Sanders, J.E., Greve, J.M., Mitchell, S.B. and Zachariah, S.G., Material properties of commonly-used interface materials and their static coefficient of friction with skin and socks, J. Rehab. Res. Dev., 35: 161-176 (1998).

[18] Dai, X., Li, Y., Zhang, M. and Cheung, J., Effect of sock on biomechanical responses of foot during walking, Clinical Biomechanics, 21: 314-321 (2006).

[19] Delporte, C., New socks offer relief, blister guard system with Teflon reduces friction between foot and sock, America's Textiles International, 26: K/A 10 (1997).

[20] Thomas, V.J., Patial, K.M. and Radhakrishnan, S., Three-dimensional stress analysis for the mechanics of plantar ulcers in diabetic neuropathy, Med. Biol. Eng. Comput., 42: 230-23 (2004).

[21] Gefen, A., Plantar soft tissue loading under the medial metatarsals in the standing diabetic foot, Med. Eng. Phys., 25: 491-499 (2003).

[22] Jacob, S. and Patil, M.K., Stress analysis in three-dimensional foot models of normal and diabetic neuropathy, Front. Med. Biol. Eng., 9: 211-227 (1999). 


\title{
تأثير خشونة سطح الأرضيات البوليمرية للمبانى الداخلية على معامل الاحتكاك
}

\author{
فوزي هاشم عزت**، أمال طه حسونهـ***، وحي بسري علي \\ كليه المندسة، جامعة المنبا، المنبا، مصرق \\ المعه العالي للتكنولوجيا، المنبا، مصر"
}

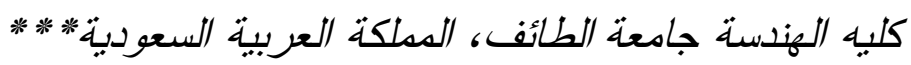

الستتخلص. يهدف هذا البحث إلى اختيار الأرضــبات البوليمريــة

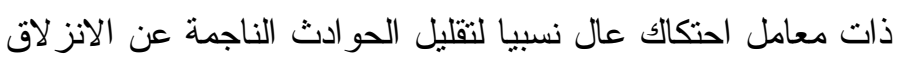
على هذه الأرضيات. يقوم هذا البحث يدرس نأثثر خشونة الـسطح

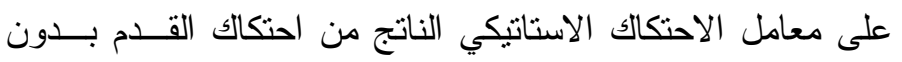

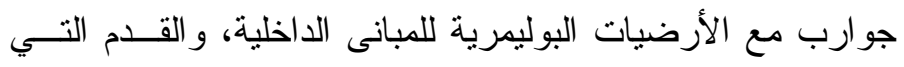

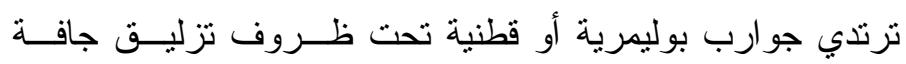
كالحجر ات و الصالات و القاعات الرياضية، أو مبللة بالماء أو مبللة

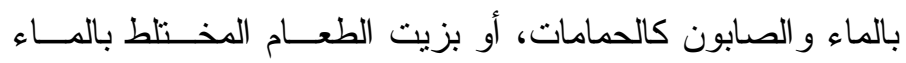

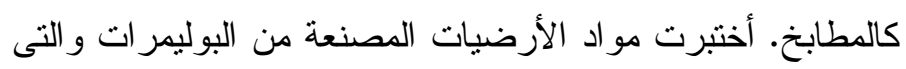

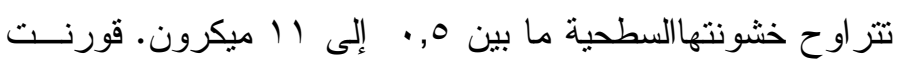

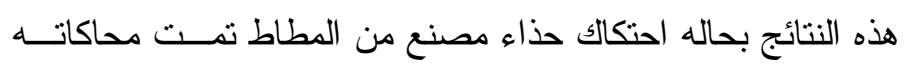

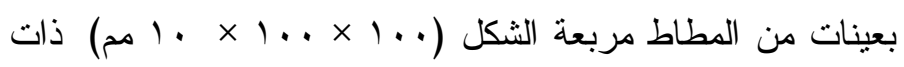
تعاريج منل أسنان المنشار .

أجريت التجارب باستخدام جهاز يقيس معامل الاحتكالك الناتج

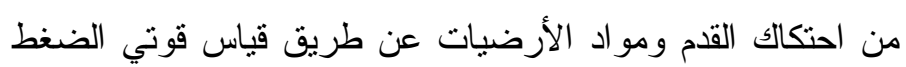

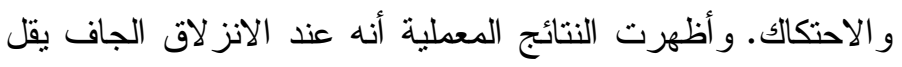

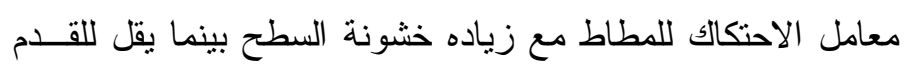


بالجو ارب البوليمريه أو بدونها إلى نهاية صغري ثم يزيــــ بعـــها

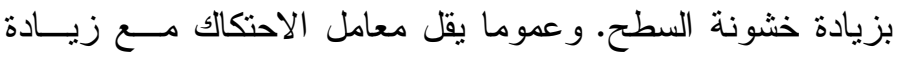

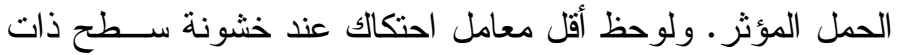
قيمة تتر اوح ما بين 1 - 9 مبكرون. أما الأسطح المبللة بالميــاه

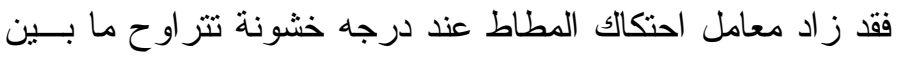

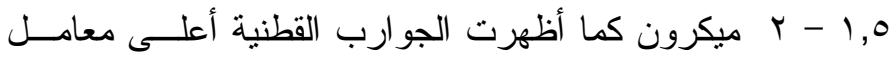

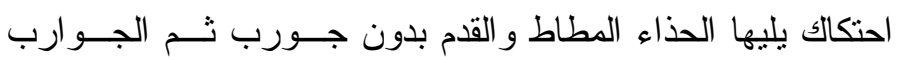

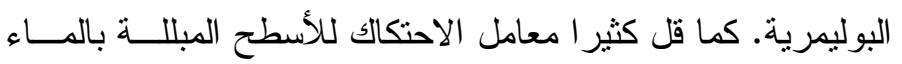

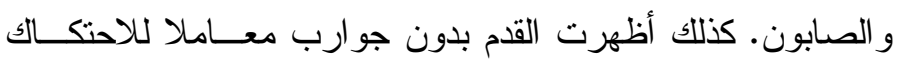

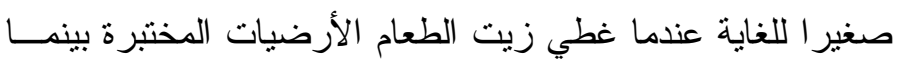

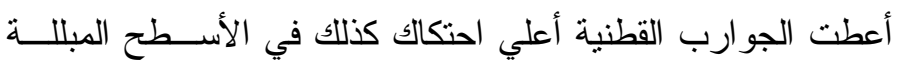
بالزيت المخلوط بالماء 